\title{
Congestive Heart Failure. Correlation Between Functional Class and Systolic and Diastolic Functions Assessed by Doppler Echocardiography
}

\author{
Cesar Selem Kamel, Aristarco G. Siqueira-Filho, Luiz Felipe Mena Barreto, Marcos Benchimol \\ Rio de Janeiro - RJ - Brazil
}

Objective - To evaluate the influence of systolic or diastolic dysfunction, or both on congestive heart failure functional class.

Methods - Thirty-six consecutive patients with a clinical diagnosis of congestive heart failure with sinus rhythm, who were seen between September and November of 1998 answered an adapted questionnaire about tolerance to physical activity for the determination of NYHA functional class. The patients were studied with transthoracic Doppler echocardiography. Two groups were compared: group 1 (19 patients in functional classes I and II) and group 2 (17 patients in functional classes III and IV).

Results - The average ejection fraction was significantly higher in group $1(44.84 \% \pm 8.04 \%$ vs. $32.59 \% \pm 11.48 \%$ with $p=0.0007)$. The mean ratio of the initial/final maximum diastolic filling velocity $(E / A)$ of the left ventricle was significantly smalleringroup $1(1.07 \pm 0.72$ vs. $1.98 \pm 1.49$ with $p=0.03)$. The average maximum systolic pulmonary venous velocity (S) was significantly higher in group $1(53.53 \mathrm{~cm} / \mathrm{s} \pm$ $12.02 \mathrm{~cm} / \mathrm{s} v \mathrm{~s} .43 .41 \mathrm{~cm} / \mathrm{s} \pm 13.55 \mathrm{~cm} / \mathrm{s}$ with $p=0.02)$. The mean ratio of maximum systolic/diastolic pulmonary venous velocity was significantly higher in group 1 (1.52 $\pm 0.48 \mathrm{vs}$. $1.08 \pm 0.48$ with $p=0.01)$. A predominance of $p$ seudo-normal and restrictive diastolic patterns existed in group $2(58.83 \%$ in group 2 vs. $21.06 \%$ in group 1 with $p=0.03$ ).

Conclusion - Both the systolic dysfunction index and the patterns of diastolic dysfunction evaluated by Doppler echocardiography worsened with the evolution of congestive heartfailure.

Keywords- congestive heart failure, functional class, systolic function, diastolic function

University Hospital Clementino Fraga Filho - UFRJ

Mailing address: Cesar Selem Kamel - Rua Tonelero, 211/501 - Rio de Janeiro, RJ - 22030-000 - Brazil - E-mail: cskamel@cardiol.br
Congestive heart failure is a complex clinical syndrome characterized by effort dyspnea, fatigue, and frequently by peripheral edema, resulting from left ventricular dysfunction. Even though the degree of dysfunction may be quantified by invasive and noninvasive diagnostic methods, the severity of the symptoms is difficult to evaluate because such an evaluation it highly subjective. Congestive heart failure is a progressive and lethal disease when untreated, and, even with the currently existing treatments, the mortality indexes remain high and the quality of life is, in general, significantly compromised. The increasing knowledge about the pathophysiology of left ventricular dysfunction, however, provides a means for efficient intervention, thus prolonging the productive life of patients.

Seeking a better understanding of this important clinical syndrome, the present study was designed for the purpose of correlating heart failure functional class (New York Heart Association) with the degree of systolic dysfunction and with the pattern of diastolic dysfunction. One third of the patients diagnosed with heart failure exhibited normal systolic function, making diastolic dysfunction the main factor responsible for the pathophysiological mechanisms in these cases ${ }^{1}$.

Controversy exists in the literature regarding the main determinants of heart failure functional class. Some studies have shown that the ability to perform physical exercises is related more to the patterns of diastolic filling of the left ventricle than to the indexes of systolic function ${ }^{2-4}$, whereas others have established a direct relationship between functional class and indexes of systolic function ${ }^{5,6}$. The more advanced functional classes (III and IV) are related to greater mortality ${ }^{1,46-10}$.

\section{Methods}

From September to November of 1998, patients with a clinical diagnosis of heart failure with sinus rhythm, who attended the Cardiology Ambulatory Clinic of the Clementino 
Fraga Filho University Hospital - UFRJ were included and directed to the Doppler echocardiography study (pulsed, continuum, and color). Patients answered a questionnaire for evaluation of functional class. All echocardiograms were performed with an Esaote 7000 Challenge apparatus, with a $2.5 \mathrm{MHz}$ transducer. Patients with mitral regurgitation with hemodynamic repercussion (area of mitral regurgitation stream $>25 \%$ of the left atrium area in the color Doppler study) and patients with a heart rate above $90 \mathrm{bpm}$ were excluded, due to interference in the flow analysis for characterizing the diastolic function. Patients with mild (small protosystolic regurgitation stream in the left atrium on pulsed Doppler, with the Doppler sample less than $1 \mathrm{~cm}$ of the mitral ring) or moderate mitral regurgitation (area of mitral regurgitation stream $\leq 25 \%$ of the left atrium area at the color Doppler) ${ }^{11}$ were kept in the study, making up 36 patients.

The patients answered the questionnaire about tolerance to several physical activities developed from data from the criteria committee of the New York Heart Association ${ }^{12}$ and from the Goldman's ${ }^{13}$ specific scale of physical activity and adapted to the Brazilian patterns to determine patients' functional classes.

The echocardiographic study recorded the degree of mitral regurgitation, the ejection fraction (Teichholz), and percentage of shortening of the left ventricle, the maximum velocity of initial diastolic filling of the left ventricle (E) and its time-velocity integral, the maximum velocity of late diastolic filling of the left ventricle (A), its time-velocity integral and duration, deceleration time of $\mathrm{E}$ (DT), isovolumetric relaxation time (IVRT), maximum systolic velocity of the pulmonary venous flow (S), the maximum diastolic velocity of the pulmonary venous flow (D), the duration of the atrium contraction retrograde pulmonary venous flow, and left ventricular diastolic pattern. The parameters described above were obtained according to the recommendations of the American Society of Echocardiography ${ }^{14}$.

In regard to diastolic function, we considered the following: a) normal pattern, a transmitral E/A ratio $>1$, with a deceleration time between 165 and $220 \mathrm{~ms}$ and isovolumetric relaxation time between 65 and 90ms, and pulmonary venous flow with S/D ratio $>1$; b) pattern of relaxation deficit, with an E/A ratio $<1$ with a deceleration time (DT) $>220 \mathrm{~ms}$ or the IVRT $>90 \mathrm{~ms}$ (or DT $>229 \mathrm{~ms}$ and IVRT $>94 \mathrm{~ms}$ in patients older than 60 years); c) pseudo-normal, an E/A ratio $>1$ with deceleration time between 165 and 220ms and IVRT between 65 and 90ms, and pulmonary venous flow with S/D ratio $<1$; d) restrictive pattern, an E/A ratio $>1$ with deceleration time $<165 \mathrm{~ms}$ and a S/D ratio $<1^{14}$.

The comparison between groups was performed with the Student's $t$ test for parametric variables, and the Chisquare or Fisher exact test to evaluate the association between the groups and nonparametric variables. The level of significance was set at $5 \%(0.05)$.

\section{Results}

Group 1 (patients in functional classes I and II) was composed of 19 patients (52.8\%) and group 2 (patients in functional classes III and IV) of 17 patients (47.2\%). Four patients (11.1\%) were in functional class I, 15 were in $(41.7 \%)$ class II, 15 $(41.7 \%)$ were in class III, and 2 (5.6\%) were in class IV.

Of the 36 patients, $22(61.1 \%)$ were men and $14(38.3 \%)$, women. The mean ages of groups 1 and 2 were $60.26 \pm 8.95$ years and $61.23 \pm 8.62$ years, respectively $(\mathrm{p}=0.74)$.

In regard to race, group 1 comprised $15(78.95 \%) \mathrm{Cau}-$ casian patients, $3(15.79 \%)$ mulatto patients, and $1(5.26 \%)$ African-Brazilian patient. Group 2 comprised 9 (52.94\%) Caucasian patients, 7 (41.18\%) mulatto patients, and 1 (5.88\%) African-Brazilian patient, with $\mathrm{p}=0.10$, where mulatto and African-Brazilian patients were pooled together for comparison purposes.

A previous history of systemic arterial hypertension was reported by 24 (66.7\%) patients, 12 patients from group 1 and 12 from group $2(\mathrm{p}=0.64)$. Ischemic heart disease was present in $30(83.3 \%)$ patients, 16 from group 1 and 14 from group $2(\mathrm{p}=0.61)$. Eleven $(0.6 \%)$ patients had a diagnosis of diabetes mellitus, 5 patients from group 1 and 6 from group $2(\mathrm{p}=0.56)$.

Regarding smoking habits, 10 (52.63\%) in group 1 and $7(41.18 \%)$ in group $2, p=0.49$, were smokers. Dyslipidemia was present in $13(68.42 \%)$ patients from group 1 and 12 $(70.59 \%)$ from group 2 , with $\mathrm{p}=0.89$.

The most frequently used medicines were angiotensin converting enzyme inhibitors by $20(56 \%)$ patients; nitrates by 11 (30.8\%); beta-blockers by 10 (28.8\%); digoxin by 6 (16.8\%); diuretics by $5(14 \%)$; and niphedipine by $5(14 \%)$ patients.

Regarding the presence and degree of mitral regurgitation, $5(26.32 \%)$ patients in group 1 did not have the condition, $12(63.16 \%)$ patients had it to a mild degree, and 2 (10.53\%) patients had it to a moderate degree. In group 2, two $(11.76 \%)$ patients did not have the condition, 9 (52.94\%) had it to a mild degree, and 6 patients (35.29\%) had it to a moderate degree, with $\mathrm{p}=0.20$.

Table 1 shows ejection fraction and fractional shortening. Tables II, III, and IV present the variables of the transmitral Doppler and the pulmonary vein. Table V contains the diastolic patterns found in both groups.

\section{Discussion}

Based on the findings of the present study, we observed the existence of an interrelation between systolic and diastolic functions. Deterioration in systolic function, judged by the more advanced functional class, is accompanied by worsening in the left ventricular diastolic pattern. This mechanism has been previously identified and reflects a decrease in ventricular compliance, as it occurs in advanced congestive heart failure ${ }^{1}$.

Several studies demonstrate greater morbidity and mortality in patients in functional classes III and IV $\mathrm{IV}^{4,6,8,9}$. Similarly, some parameters of diastolic function, such as short deceleration time $(<140 \mathrm{~ms})$, high E/A ratio $(>1)$, a restrictive diastolic pattern in the left ventricle and a high maximum Evelocity in transmitral flow, are important mortality predictors in congestive heart failure patients ${ }^{4,8-10,15,16}$. In the present stu- 


\begin{tabular}{|lccc|}
\hline \multicolumn{4}{|c|}{ Table I - Ejection fraction and fractional shortening } \\
\hline Variable & Subjects & Mean & P \\
\hline G1-FE & 19.00 & 44.84 & \\
G2-FE & 17.00 & 32.59 & 0.0007 \\
G1-fr. short. & 19.00 & 23.16 & \\
G2-fr. short. & 17.00 & 16.00 & 0.0004 \\
\hline G1 - group 1; G2 - group 2; EF - ejection fraction; fr. short. - fractional \\
shortening.
\end{tabular}

\begin{tabular}{|c|c|c|c|}
\hline \multicolumn{4}{|c|}{ Table II - Variables of the transmitral Doppler study } \\
\hline Variable & Subjects & Mean & $\mathrm{P}$ \\
\hline G1- E & 19.00 & 62.53 & \\
\hline G2- E & 17.00 & 76.47 & 0.0800 \\
\hline G1- A & 19.00 & 66.21 & \\
\hline G2- A & 17.00 & 55.18 & 0.1500 \\
\hline G1-E/A ratio & 19.00 & 1.07 & \\
\hline G2-E/A ratio & 17.00 & 1.98 & 0.0300 \\
\hline G1-TD & 19.00 & 180.26 & \\
\hline G2-TD & 17.00 & 148.70 & 0.0800 \\
\hline $\begin{array}{l}\text { G1- group } 1 ; C \\
\text { A velocity - } \mathrm{Cr}\end{array}$ & up 2 ; E- 1 & $\begin{array}{l}\text { ocity - c } \\
\text { tion tim }\end{array}$ & maximum \\
\hline
\end{tabular}

\begin{tabular}{|c|c|c|c|}
\hline \multicolumn{4}{|c|}{ Table III - Variables of transmitral Doppler and of IVRT } \\
\hline Variable & Subjects & Mean & $\mathrm{p}$ \\
\hline G1-A leng. & 19.00 & 146.53 & \\
\hline G2-A leng. & 17.00 & 140.18 & 0.5200 \\
\hline G1-Ei & 19.00 & 8.42 & \\
\hline G2-Ei & 17.00 & 8.65 & 0.8100 \\
\hline G1-Ai & 19.00 & 5.95 & \\
\hline G2-Ai & 17.00 & 5.18 & 0.3900 \\
\hline G1-TRIV & 19.00 & 112.05 & \\
\hline G2-TRIV & 17.00 & 104.29 & 0.3600 \\
\hline \multicolumn{4}{|c|}{$\begin{array}{l}\text { G1- group 1; G2- group } 2 \text {; A leng. - length of A - ms; Ei and Ai } \\
\text { integral of E and A velocities, respectively; IVRT- isovolumetric rela- } \\
\text { xation time - ms }\end{array}$} \\
\hline
\end{tabular}

dy, it was possible to correlate functional classes III and IV with pseudo-normal and restrictive diastolic patterns.

A correlation exists between left ventricular diastolic function and hemodynamic parameters. The restrictive pattern of transmitral flow and the short deceleration time are correlated with elevated pulmonary capillary pressure ${ }^{17,18}$. Likewise, the increased maximum diastolic velocity of pulmonary venous flow (D) is associated with elevated pulmonary capillary pressure ${ }^{19}$.

The elevated E/A ratio of the transmitral flow, the short deceleration time, the reduced S/D ratios of the pulmonary venous flow, the lower $\mathrm{S}$ pulmonary venous velocity

\begin{tabular}{|lccc|}
\hline \multicolumn{4}{|c|}{ Table IV - Variables of pulmonary venous Doppler } \\
\hline Variable & Subjects & Mean & $\mathrm{P}$ \\
\hline G1-S & 19.00 & 53.53 & \\
G2-S & 17.00 & 43.41 & 0.0200 \\
G1-D & 19.00 & 37.05 & \\
G2-D & 17.00 & 42.88 & 0.1100 \\
G1-S/D ratio & 19.00 & 1.52 & \\
G2-S/D ratio & 17.00 & 1.08 & 0.0100 \\
& & & \\
G1-Ar leng. & 19.00 & 169.53 & \\
G2-Ar leng. & 17.00 & 176.70 & 0.6200 \\
& & & \\
G1-A / A r & 19.00 & 0.90 & 0.6900 \\
G2-A / A r & 17.00 & 0.86 & \\
\hline
\end{tabular}

G1- group 1; G2- group 2; S- maximum systolic velocity of pulmonary venous flow $-\mathrm{cm} / \mathrm{s}$; D- maximum diastolic velocity of pulmonary venous flow - $\mathrm{cm} / \mathrm{s}$; S/D ratio - ratio between maximum systolic velocity of pulmonary venous flow and maximum diastolic velocity of pulmonary venous flow; Ar leng. - length of retrograde $\mathrm{A}$ in pulmonary vein; $\mathrm{A} / \mathrm{Ar}-$ A length/retrograde A length ratio in pulmonary vein.

\begin{tabular}{|lcc|}
\hline \multicolumn{3}{|c|}{ Table V - Diastolic patterns } \\
\hline & Group 1 & Group 2 \\
\hline Normal & $5(26.32 \%)$ & 0 \\
Alt. Relax. & $10(52.63 \%)$ & $7(41.18 \%)$ \\
Pseudo & $2(10.53 \%)$ & $3(17.65 \%)$ \\
Restrictive & $2(10.53 \%)$ & $7(41.18 \%)$ \\
\hline Alt. Relax. - Altered relaxation and pseudo (pseudo-normal). There is a \\
predominance of pseudo-normal and restrictive patterns in group 2, with \\
p=0.03, when compared to normal cases. \\
\hline
\end{tabular}

and the pseudo-normal and restrictive diastolic patterns served to characterize functional classes III and IV. Similarly, the lower ejection fraction and fractional shortening together with the more severe systolic dysfunction also characterize functional classes III and IV. More recently, the tissue Doppler and color M-mode Doppler techniques of mitral flow propagation have facilitated the characterization of left ventricular diastolic filling patterns.

According to several studies ${ }^{20-27}$, other factors, such as the use of correct medication, especially angiotensin converting enzyme inhibitors, may also influence functional class. In the present study, $56 \%$ of the patients regularly used some type of angiotensin converting enzyme inhibitor, without differences between groups. It is interesting to note the low percentage of use of angiotensin converting enzyme inhibitors (which are well known to reduce morbidity andmortality in cases of congestive heart failure) probably due to low adherence to the treatment.

The question of drug treatment for congestive heart failure and the pattern of diastolic filling of the left ventricle was explored by Keren et $\mathrm{al}^{22}$, who demonstrated that the maximum velocity of initial diastolic filling (E) decreases with treatment and is associated with a longer period of 
exercise and improvement in functional class. Similarly, other researchers have demonstrated that the patterns of diastolic filling of the left ventricle might change from one type to the other, with the patients' clinical improvement and the optimization of treatment ${ }^{4,15,22-28}$. The restrictive pattern of the left ventricle, which remains unaltered despite the optimization of treatment for congestive heart failure, has been pointed out as an important marker of clinical deterioration and worsening in functional class in patients with dilated myocardiopathy, according to Shen et a ${ }^{15}$. The clinical and functional class improvement in congestive heart failure patients is accompanied by a reduction in the $\mathrm{E} / \mathrm{A}$ transmitral flow ratio and by an augmentation of the deceleration time ${ }^{15}$.

Reports exist in the literature about functional class improvement in patients who undergo physical training. It is known that one of the adaptive mechanisms of congestive heart failure consists of physical conditioning loss resulting from a decrease in peripheral tissue perfusion. Magnusson et $\mathrm{al}^{29}$ demonstrated that alterations in skeletal muscles in congestive heart failure are not entirely irreversible. Localized muscle training is efficient and may result in a marked augmentation of the local work capacity and in a small increase in the total work capacity. In trained patients, an increase in the quadriceps muscle transverse area, an increase in the capillary/fiber index, and an increase in oxidative enzymatic activity have been demonstrated ${ }^{29}$. These factors might explain some discrepancies found in the present study, such as the presence of 2 patients with pseudo-normal diastolic pattern and 2 others in group 1 with a restrictive pattern.

The better comprehension of these mechanisms, obtained by a judicious study of the echocardiographic parameters used in the characterization of degrees of systolic, or diastolic dysfunctions, or both, helps the identification of patients who will, possibly, have a more unfavorable clinical evolution.

\section{References}

1. Nishmura RA, Tajik J. Evaluation of diastolic filling of left ventricle in health and desease: doppler echocardiography is the clinician's rosetta stone. J Am Coll Cardiol 1997; 30: 8-18.

2. Davies SW, Fussell AL, Jordan SL, et al. Abnormal diastolic filling patterns in chronic heart failure - relationship to exercise capacity. Eur Heart J 1992; 13: 749-57.

3. Miyagi K, Asanoi H, Ishizaka S, et al. Limited value of anaerobic threshold for assessing functional capacity in patientes with heart failure. Clin Cardiol 1993; 16: 133-7.

4. Traversi E, Pozzoli M, Cioffi G, et al. Mitral flow velocity changes after 6 months of optimized therapy provide important hemodynamic and prognostic information in patients with chronic heart failure. Am Heart J 1996; 132: 809-19.

5. Finkelhor RS, Sun JP, Castellanos M, et al. Predicting left heart failure after a myocardial infarction: a preliminary study of the value of echocardiographic measures of left ventricular filling and wal motion. J Am Soc Echocardiogr 1991; 4: 215-23.

6. Van den Broek SA, van Veldhuisen DJ, de Graeff PA, et al. Comparison between New York Heart Association Classification and peak oxygen consumption in the assessment of functional status and prognosis in patients with mild to moderate chronic congestive heart failure secondary to either ischemic or idiopathic dilated cardiomyopathy. Am J Cardiol 1992; 70: 359-63.

7. Gianuzzi P, Temporelli PL, Bosimini E, et al. Independent and incremental prognostic value of doppler-derived mitral deceleration time of early filling in both symptomatic and asymptomatic patients with left ventricular dysfunction. J Am Coll Cardiol 1996; 28: 383-90.

8. Pozzoli M, Capomolla S, Sanarico M, et al. Doppler evaluation of left ventricular diastolic filling and pulmonary wedge pressure provide similar prognostic information in patients with systolic dysfunction after myocardiol infarction. Am Heart J 1995; 129: 716-25.

9. Giannuzzi P, Temporelli PL, Bosimini E, et al. Independent and incremental prognostic value of doppler-derived mitral deceleration time of early filling in both symptomatic and asymptomatic patients with left ventricular dysfunction. J Am Coll Cardiol 1996; 28: 383-90.

10. Nijland F, Kamp O, Karreman AJ, et al. Prognostic implications of restrictive left ventricular filling in acute myocardial infarction: a serial doppler echocardiographic study. J Am Coll Cardiol 1997; 30: 1618-24.

11. Helmcke F, Nanda NC, Hsuing MC, et al. Color Doppler assessment of mitral regurgitation with orthogonal planes. Circulation 1987; 75: 175-83.

12. The CRITERIA Committee of the New York Heart Association: Diseases of the Heart and Blood Vessels; Nomenclature and Criteria for Diagnosis. $6^{\text {th }}$ edition, Boston: Little, Brown and Co., 1964. In: Braunwald E. Heart Disease: A Textbook of Cardiovascular Medicine, $4^{\text {th }}$ edition. Philadelphia: WB Saunders, 1992; cap I: p. 12.

13. Goldman L, Hashimoto B, Cook EF, et al. Comparative reproducibility and validity of systems for assessing cardiovascular functional class: advantages of a new specific activity scale. Circulation 1981; 64: 1227.

14. Feigenbaum H. Echocardiography. Echocardiographic Evaluation of Cardiac Chambers. Williams and Wilkins. $5^{\text {th }}$ Edition, 1994; Cap. 3.
15. Shen WF, Tribouilloy C, Rey JL, et al. Prognostic significance of Doppler-derived left ventricular diastolic filling variables in dilated cardiomyopathy. Am Heart J 1992; 124: 1524-33.

16. Werner GS, Schaefer C, Dirk R, et al. Prognostic value of Doppler echocardiographic assessment of left ventricular filling in idiopathic dilated cardiomyopathy. Am J Cardiol 1994; 73: 792-8.

17. Giannuzzi P, Shabetai R, Imparato A, et al. Effects of mental exercise in patients with dilated cardiomyopathy and congestive heart failure. An echocardiographic Doppler study. Circulation 1991; 83: 4(suppl): II 155-II 165.

18. Masuyama T, Lee JM, Nagano R, et al. Doppler echocardiography pulmonary flow-velocity pattern for assessment of the hemodynamic profile in acute congestive heart failure. Am Heart J 1995; 129: 107-13.

19. Ogawa $\mathrm{S}$, Oki T, Iuchi A, et al. Evaluation of pulmonary venous flow patterns in left heart failure: a study using transesophageal Doppler echocardiography. J Cardiol 1993; 23: 193-204

20. The CONSENSUS Trial Study Group: Effects of Enalapril on Mortality in Severe Congestive Heart Failure. N Engl J Med 1987; 316: 1429-35.

21. The SOLVD Investigators: Effects of enalapril on survival in patients with reduced left ventricular ejection fraction and congestive heart failure. $\mathrm{N}$ Engl $\mathrm{J} \mathrm{Med}$ 1991; 325: 293-302.

22. Keren G, Pardes A, Eschar Y, et al. Left ventricular filling dynamics by Doppler echocardiography in dilated cardiomyopathy: one-year follow-up in patients treated with captopril compared to placebo. Cardiology 1992; 81: 196-206.

23. Iga K, Hori K, Matsumura T, et al. Left ventricular filling pattern in congestive heart failure patients with normal sinus rythm - a decreased ratio of peak mitral flow velocity in atrial systole relative to that in early diastole may reflect markedly increased left ventricular end-diastolic pressure. Jpn Circ J 1990; 54: 473-7.

24. Giunta A, Maione S, Arnese MR, et al. Effects of intravenous digoxin on pulmonary venous and transmitral flows in patients with chronic heart failure of different degrees. Clin Cardiol 1995; 18: 27-33.

25. Yamamuro A, Yoshida K, Akasaka T, et al. Prognostic value of serial Doppler echocardiography follow-up of transmitral flow patters in patients with congestive heart failure who presented with pulmonary edema. J Cardiol 1996; 27: 321-7.

26. Andersson B, Caidahl K, di Lenarda A, et al. Changes in early and late diastolic filling patterns induced by long-term adrenergic beta-blockade in patients with idiopathic dilated cardiomyopathy. Circulation 1996; 94: 673-82.

27. Litwin SE, Katz SE, Morgan JP, et al. Long-term captopril treatment improves diastolic filling more than systolic performance in rats with large myocardial infarction. J Am Coll Cardiol 1996; 28: 773-81.

28. Ito T, Suwa M, Kobashi A, et al. Reversible left atrial dysfunction possibly due to afterload mismatch in patients with left ventricular dysfunction. J Am Soc Echocardiogr 1998; 11: 274-9.

29. Magnusson G, Gordon A, Kaijser L, et al. High intensity knee extensor training, in patients with chronic heart failure. Major skeletal muscle improvement. Eur Heart J 1996; 17: 1048-55. 